\title{
Isolated Migratory Stomatitis: Report of A Rare Case
}

Garma $\mathrm{M}^{1 *}$, Hasni $\mathrm{W}^{1}$, Hassouna $\mathrm{M}^{1}$, Messaoud NB${ }^{1}$, Youssef $\mathrm{SB}^{1}$, Boughzela $\mathrm{A}^{2}$

${ }^{1}$ Department of Oral Medicine and Oral Surgery, Farhat Hached Hospital, Faculty of Dentistry, University of Monastir, Tunisia.

${ }^{2}$ Division of Dental Medicine, Farhat Hached Hospital, Head of Division, Tunisia.

\section{Abstract}

Introduction: Geographic stomatitis is a rare benign inflammatory lesion of the oral mucosa. The most common involved site is the tongue but any area of oral mucosa can be affected. Regarding its rarity and, sometimes, its inchoate clinical appearance, this condition remains not well-known by the physicians. What motivated this article. The aim was to examine the clinical and histological features of this condition and it'is therapeutic approach by reporting a case of geographic stomatitis in a young adult patient.

Observation: A 27-year-old male patient consulted with the chief complain of periodental care. The oral examination revealed multiple erythematous asymptomatic areas in the oral mucosa. Clinical and histological finding confirmed the diagnosis of geographic stomatitis.

Discussion: Geographic or migratory stomatitis represents a very rare benign condition affecting $1 \%$ of the population, most commonly the females. Its etiology remains unknown. It usually involves the tongue surface and known as geographic tongue, but can also affect some ectopic areas such as labial and buccal mucosa, soft palate, vestibule and flour of the mouth.

The clinical features are pathognomonic and can lead to the diagnosis but the histological examination remains necessary for the diagnosis confirmation. It showed parakeratosis and elongation of rete ridges, in addition to an inflammatory infiltrate with the characteristic Munro microabscesses and pustules of Kogoj. Treatment of this lesion depends on symptoms; therefore the abstention is the usual attitude.

Keywords: Oral Mucosa; Benign Migratory Glossitis; Erythema Migrans; Psoriasis; Diagnosis Oral.

\section{Introduction}

Geographic stomatitis is a rare benign condition first described by Cooke in 1955, involving any area of the oral mucosa, frequently the tongue where it 'is known as the famous geographic tongue. Due to it'is uncommon and asymptomatic clinical presentation, this lesion remains unknown by physicians.

A rare case of geographic stomatitis is reported in order to remind the clinical and histological features of this oral lesion as well as therapeutic attitudes reported in the literature.

\section{Case Report}

A 27-year-old male patient consulted for periodontal care. At an- amnesis, he reported that he has been aware, since few months, of the presence of asymptomatic "red-white" lesions in his oral mucosa. The extra oral examination was normal. His familial and post medical history were non-contributory.

The intra oral examination showed a multiple oval to circinate red patches on the labial, buccal (Figure 1a, 1b) and lingual mucosa (Figure 2a) surrounded by a keratotic yellowish white border. Deep fissures on the lingual dorsum with a depapillated areas were revealed (Figure $2 \mathrm{~b}$ ).

Lesions were completely asymptomatic. A biopsy was performed. histologically, the lesion presents an hyperplastic squamous epithelium, parakeratosis and acanthosis with elongation of rete ridges, Superficial and perivascular lymphocytic inflammatory cell infiltrate with dilated tortuous vessels and exocytosis of polymor-

\footnotetext{
*Corresponding Author:

Maroua Garma,

Department of Oral Medicine and Oral Surgery, Farhat Hached Hospital, Faculty of Dentistry, University of Monastir, Tunisia.

E-mail: marwa.garma@yahoo.fr
}

Received: October 19, 2018

Accepted: November 12, 2018

Published: November 14, 2018

Citation: Garma M, Hasni W, Hassouna M, Messaoud NB, Youssef SB, Boughzela A. Isolated Migratory Stomatitis: Report of A Rare Case. Int J Clin Dermatol Res. 2018;6(8):190-192. doi: http://dx.doi.org/10.19070/2332-2977-1800045

Copyright: Garma $\mathbf{M}^{\circ}$ 2018. This is an open-access article distributed under the terms of the Creative Commons Attribution License, which permits unrestricted use, distribution and reproduction in any medium, provided the original author and source are credited. 
Figure 1a. Circinate red areas in the lower labial mucosa surrounded by a yellowish white border.

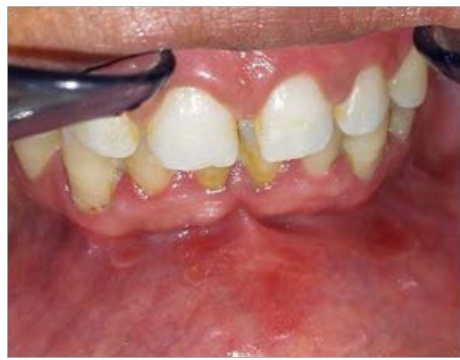

Figure 1b. Erythematous oval macules of $0.5 \mathrm{~cm}$ of diameter in the buccal right mucosa.

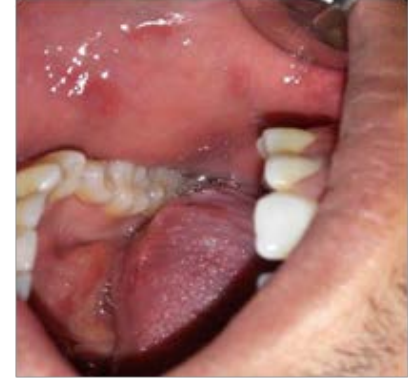

Figure 2a. Circinate red patches surrounded by a yellowish white border in the lateral right border of the tongue.

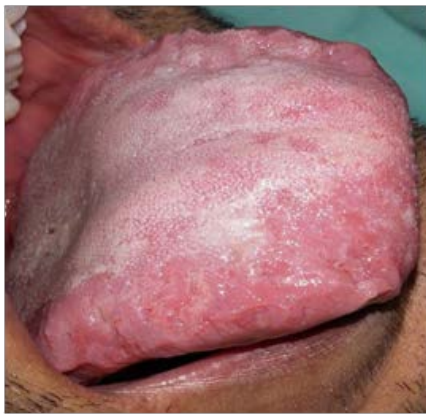

Figure 2b. Fissures and depapillated areas on the lingual dorsum.

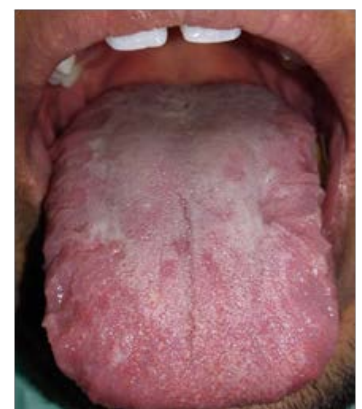

phonuclear leukocytes were revealed. Munro microabcesses and pustules of Kogoj were also identified (Figure 3).

Clinical and histological finding confirmed the diagnosis of geographic stomatitis.

In this case, regarding the absence of symptoms, the therapeutic approach was the abstention with recommendation of consulting once symptoms appear.

\section{Discussion}

Geographic stomatitis is a rare inflammatory benign lesion that have been described by various names in the literature since it was originally reported in 1955 by Cooke [1-3], including annulus migrans, erythema migrans, ectopic geographic tongue, Cooke's disease, migratory stomatitis, erythema circinate migrans, migratory mucositis and stomatitis areata migrans $[1,4]$.

It affects about $1 \%$ of the population and can occur in children or adults but most commonly in females.

This condition can involve in any area of the oral mucosa, most commonly in the tongue, then the buccal mucosa, the lower labial mucosa, the muccobuccal fold, vestibule, floor of the mouth, lips and rarely the soft palate $[1,2,5,6]$. In the majority of cases, all patients with geographic stomatitis present geographic and fissured tongue but not almost patients with geographic tongue have geographic stomatitis [1]. For our patient, the two lesions are identified.

The etiology of this lesion remains unknown $[1,2,7]$, unless 
Figure 3. Hyperplastic squamous epithelium, parakeratosis and acanthosis with elongation of rete ridges, besides to superficial and perivascular lymphocytic inflammatory cell infiltrate with dilated tortuous vessels and exocytosis of polymorphonuclear leukocytes associated with the presence of Munro microabscesses and pustules of Kogoj.
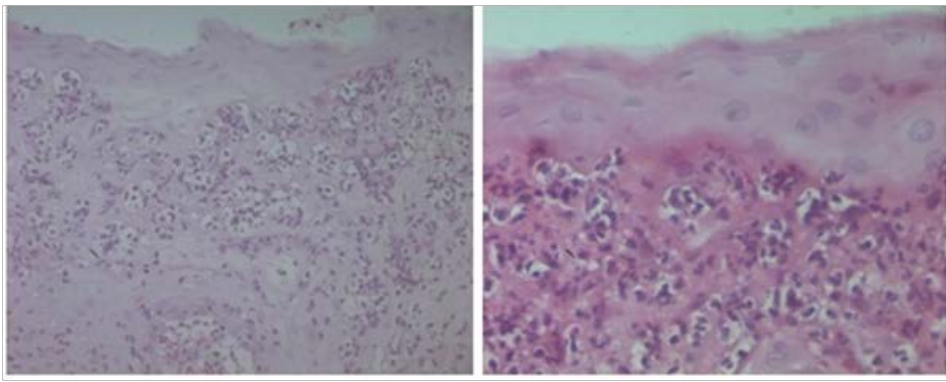

some authors suggest a possible link between geographic stomatitis and immune mediated diseases such as psoriasis, regarding the similarity of their histopathological and genetic features [2, 8]. Then; Some authors consider that migratory stomatitis may be an oral manifestation of psoriasis, in this context many cases of geographic stomatitis associated to psoriasis were reported $[2,5$, 9]. This link was eliminated in our case based on a dermatological examination. A connection with seborrheic dermatitis, Reiter's syndrome and crohn's disease $[5,7,9]$ was also suggested.

The diagnosis of this condition can be concluded from the clinical features whish are pathognomonic. In fact lesions appear as well-demarcated erythematous circinate patches surrounded by a yellowish-white keratotic slightly elevated border $[1,2,5,8]$. Besides the tongue presents characteristic erythematous depapillated areas in the tongue (corresponding to the loss of the filiform papillae and the thinning of the epithelium), as well as a white border resulting to the regenerating filiform young papillae that are whiter than the rest of the tongue surface [1]. However, when lesions are in remission, clinical appearance is less evocative. The reported case was very characteristic.

Although the diagnosis of geographic stomatitis was evoked from the clinical appearance, histological confirmation was required. Histological features are parakeratosis with regular elongation of rete ridges associated to acanthosis and clubbing, in addition to a suprapapillary thinning of the epithelium with the presence of spongiform pustules of Kogoj. The perivascular surface and the submucosa present a dense inflammatory cell infiltrate with polymorphonuclear leukocytes and lymphocytes migration into the epithelial degeneration zone, associated to the proliferation of Munro's microabscesses [1, 2, 9, 10]. All these features were identified in our case Where the biopsy was dictated by an anxious profile of the patient.

Differential diagnosis includes lichen planus, oral candidiosis, lupus erythematous, recurrent aphthous stomatitis $[1,5,7]$.

All forms of geographic stomatitis are characterized by periods of exacerbation and remission $[1,7]$. These lesions are usually asymptomatic and discovered in a routine oral examination. When they are present, symptoms are dominated by a discomfort: tenderness or burning sensation, but also sensitivity with spicy, hot or acidic foods, cheese and alcoholic beverages $[5,7]$.

The therapeutic approach depends on the presence of symptoms: in case of asymptomatic form, geographic stomatitis is a benign condition that doesn't need any intervention and we can just recommend an oral and food hygiene to avoid exacerbation. But when symptoms are present, they require a palliative antalgique treatment like topical corticosteroids or topical anesthetics. Some successful cases of treatment of migratory stomatitis by systemic retinoid acid were reported. Use of topical or systemic antihistamines was also suggested $[1,5,7]$.

\section{Conclusion}

Contrary to geographic tongue which has a pathognomonic aspect, migratory stomatitis can confuse clinician, a detailed examination of the oral mucosa and a biopsy lead to define the diagnosis.

\section{References}

[1]. Brooks JK, Balciunas BA. Geographic stomatitis: review of the literature and report of five cases. J Am Dent Assoc. 1987 Sep;115(3):421-4. PubMed PMID: 3476662.

[2]. Picciani B, Silva-Junior G, Carneiro S, Sampaio AL, Goldemberg DC, Oliveira J, et al. Geographic stomatitis: an oral manifestation of psoriasis?. J Dermatol Case Rep. 2012 Dec 31;6(4):113-6. doi: 10.3315/ jdcr.2012.1118. PubMed PMID: 23329990.

[3]. Cooke BE. Erythema migrans affecting the oral mucosa. Oral Surg Oral Med Oral Pathol. 1955 Feb;8(2):164-7. PubMed PMID: 13236303.

[4]. Donelli RA. Geographic stomatitis (tongue and mucosae). InJ Clin Stomatol Conf. 1964;5(1):21-22.

[5]. Flaitz CM. Ectopic erythema migrans in an adolescent with a skin disorder. Pediatr Dent. 2000 Jan-Feb;22(1):63-4. PubMed PMID: 10730290.

[6]. Scully C. Erythema migrans. Oral and maxillofacial medicine. 2nd ed. Edinburgh (UK): Elsevier; 2008. p. 205-6.

[7]. Zadik Y, Drucker S, Pallmon S. Migratory stomatitis (ectopic geographic tongue) on the floor of the mouth. J Am Acad Dermatol. 2011 Aug;65(2):459-460. doi: 10.1016/j.jaad.2010.04.016. PubMed PMID: 21763590 .

[8]. Espelid M, Bang G, Johannessen AC, Leira JI, Christensen O. Geographic stomatitis: report of 6 cases. J Oral Pathol Med. 1991 Oct;20(9):425-8. PubMed PMID: 1804987.

[9]. Van der Wal N, Van Der Kwast W, Van Dijk E, Van der Waal I. Geographic stomatitis and psoriasis. Int J Oral Maxillofac Surg. 1988 Apr;17(2):106-9. PubMed PMID: 3133417.

[10]. Warnock GR, Correll RW, Pierce GL, Hatch CL. Multiple, shallow, circinate mucosal erosions on the soft palate and base of uvula. J Am Dent Assoc. 1986 Apr;112(4):523-4. PubMed PMID: 3457857. 